\title{
Natural convection in evaporating sessile drops with solidification
}

\author{
YEONG-JEN SU, WEN-JEI YANG and G. KAWASHIMA† \\ Department of Mechanical Engineering and Applied Mechanics, University of Michigan, \\ Ann Arbor, MI 48109, U.S.A.
}

(Received 10 August 1987)

\begin{abstract}
Transient natural convection and internal solidification in a minute drop evaporating on a horizontal plate is investigated by the laser shadowgraph-schlieren method and direct microscopic photography. The drop is point-cooled at the center of the base by the tip of a metal wire connected to a block of dry ice. A thermocapillary-induced, doughnut-shaped vortex region exists around the solid phase during the course of internal solidification. The genesis of a thermocapillary-induced vortex ring and internal solidification can be predicted from the time history of drop temperatures. The internal solidification suppresses the surface rippling of an evaporating drop, thus retarding the evaporation rate. Empirical expressions are obtained which describe the effects of the Marangoni, Prandtl and Stefan numbers and the degree of supercooling on the solid growth velocity.
\end{abstract}

\section{INTRODUCTION}

HEAT TRANSFER and fluid flow associated with solidliquid phase change are of importance in a broad range of technology and geophysics. Some common examples include the freezing of lake surfaces, the latent heat type energy storage in solar energy systems, solid-fuel tanks, and nuclear reactor safety problems concerning the interaction between a molten $\mathrm{UO}_{2}$ pool and a refractory material such as $\mathrm{MgO}$. Moreover, solidification combined with natural convective transfer near the free surface is the key phenomena in various casting processes and crystal growth.

Much of the early work on the problems involving solid liquid phase change was confined essentially to the cases in which the liquid is stagnant or liquid motion is entirely induced by the phase-change process itself. This heat-diffusion controlled freezing or melting problem was pioneered by Stefan in 1891 . Several survey articles can be found in refs. [1-3]. The problems concerned with solid-liquid phase change in a fluid in motion have attracted considerable attention during the last two decades. They involve not only convective heat transfer but also solidification morphology coupled with hydrodynamic instability at the phase interface. Comprehensive reviews of the literature pertinent to the problems of convection accompanied by solid-liquid phase change are available in refs. [4-7]. Those reviews have disclosed that most effort has been focused on the influences of buoy. ancy force on flow and instability phenomena, while little attention has been directed toward the effects of

† Visiting scholar on leave from the Department of Mechanical Engineering, Musashi Institute of Technology, Tokyo, Japan. thermocapillary-induced natural convection on the growth of solidification.

In a reduced-gravity environment or for a fluid system having an extremely small characteristic length, thermocapillary-induced convection is dominant because of negligible buoyancy. Surface tension is a function of temperature, composition and electrical potential. The gradients of any one of these three or their combinations will lead to surface-tension gradients which induce thermocapillary effects: Marangoni instability and Marangoni convection [8]. The Marangoni instability refers to the flow induced by ever-present small disturbances under unstable density stratification. In this case, the surface-tension gradient is normal to the interface and the fluid motion could appear cellular in structure. The phenomena was identified as 'interfacial turbulence' by Sternling and Scriven [9] and 'form of interfacial turbulence' by Kenning [10]. If the gradients act along the interface, the fluid motion thus initiated is called Marangoni convection. To simulate thermocapillary flows terrestrially, Chun and Wuest [11] carried out experiments with a silicon coil between two vertical coaxial discs. The discs with a $1 \mathrm{~mm}$ gap were electrically heated to a temperature difference of up to $50^{\circ} \mathrm{C}$, with the appearance of a simple vortex. Schwabe et al. [12] observed a similar vortex by melting $\mathrm{NaNO}_{3}$ in a small gap. The thermocapillary-induced velocity on the free surface was estimated to be 11-17 $\mathrm{mm} \mathrm{s}^{-1}$. Experimental studies were conducted on the natural convection patterns in sessile drops evaporating on a horizontal plate [13]. Duh [14] numerically studied natural convection in an evaporating sessile drop. Both concluded the dominant role of the thermocapillary force in natural convection and thermal stability in the drops.

In the present study, a heat sink was installed at the 


\section{NOMENCLATURE}

$A$ aspect ratio, $R / L ; R_{\mathrm{s}} / l$ for sessile drop

a thermal diffusivity $\left[\mathrm{m}^{2} \mathrm{~s}^{-1}\right]$

$B d$ dynamic Bond number, $\rho g \beta l^{2} /(\partial \sigma / \partial T)$

$B o$ Bond number, $\rho g l^{2} / \sigma$

$C_{n} \quad$ specific heat $\left[\mathrm{kJ} \mathrm{kg}^{\prime \prime} \mathrm{K}^{-1}\right]$

$g$ gravitational acceleration $\left[\mathrm{m} \mathrm{s}^{-2}\right]$

$h$ heat transfer coefficient between the solid and liquid phases $\left[\mathrm{kW} \mathrm{m}^{-2} \mathrm{~K}^{-1}\right]$

$h_{\mathrm{ss}} \quad$ heat of fusion $\left[\mathrm{kJ} \mathrm{kg}^{-1}\right]$

$k$ thermal conductivity $\left[\mathrm{kW} \mathrm{m}^{-1} \mathrm{~K}^{-1}\right]$

$L \quad$ height of sessile drop [m]

$l$ characteristic length $[\mathrm{m}]$

$\mathrm{Ma}$ Marangoni number, $(\partial \sigma / \partial T) \Delta T / /(\mu a)$

$\mathrm{Nu}$ Nusselt number, $h l / k$

$P e \quad$ Peclet number, $U R / a$

Pr Prandtl number, $v / a$

$R \quad$ radius of drop base $[\mathrm{m}] ; R_{1}, R_{2}$, radii of curvature

$R a$ Rayleigh number, $\rho g \beta \Delta T l^{3} /(\mu a)$

$R_{\mathrm{s}} \quad$ base radius of solid phase [m]

$r$ coordinate $[\mathrm{m}]$

$S$ degree of supercooling in dimensionless form, $C_{p s}\left(T_{\mathrm{m}}-T_{1}\right) / h_{1 \mathrm{~s}}$

St Stefan number, $C_{p !}\left(T_{2}-T_{\mathrm{m}}\right) / h_{\mathrm{ls}}$

$T$ drop temperature [ $\left.{ }^{\circ} \mathrm{C}\right] ; T_{1}$, at base center; $T_{1 \text { min }}$, minimum value of $T_{1} ; T_{2}$, at base edge (triphase line); $T_{3}$, at summit
$T_{\mathrm{e}} \quad$ equivalent temperature of solid-liquid interface $\left[{ }^{\circ} \mathrm{C}\right]$

$T_{\mathrm{m}}$ melting temperature $\left[{ }^{\circ} \mathrm{C}\right]$

$t \quad$ time $[\mathrm{s}] ; t_{\min }$, at $T_{1}=T_{1 \min }$

$V$ drop volume $\left[\mathrm{m}^{3}\right]$

$v \quad$ solidification front velocity $\left[\mathrm{m} \mathrm{s}^{-1}\right]$

$v^{*} \quad A\left(v R_{\mathrm{s}} / a_{\mathrm{s}}\right) M a^{1 / 4} \mathrm{Pr}^{4} \mathrm{St}^{1 / 8}$

$z \quad$ coordinate $[\mathrm{m}]$.

\section{Greek symbols}

$\beta \quad$ coefficient of thermal expansion $\left[\mathrm{K}^{-1}\right]$

$\gamma \quad$ surface energy $\left[\mathrm{kJ} \mathrm{m}^{-2}\right]$

$\mu \quad$ dynamic viscosity $\left[\mathrm{N} \mathrm{s} \mathrm{m}^{-2}\right]$

$v \quad$ kinematic viscosity $\left[\mathrm{m}^{2} \mathrm{~s}^{-1}\right]$

$\rho$ densily $\left[\mathrm{kg} \mathrm{m}^{-3}\right]$

$\sigma \quad$ surface tension $\left[\mathrm{Nm}^{-1}\right]$.

\section{Subscripts}

1 liquid phase

m melting point

s solid phase

1 base center of sessile drop

2 base edge of sessile drop (triphase line)

3 drop summit center of the base of an evaporating sessile drop to promote radially outward solidification within the drop. The buoyancy effect is negligibly small due to the small characteristic length, while the thermocapillary force becomes dominant owing to the surface temperature gradient and drop curvature. The drop morphology, internal flow patterns, drop temperature variation and solidification front movement during the phase change are visualized by the shadowgraph-schlieren method and direct microscopic photography. Empirical equations are derived for the relationship between the solidification front velocity and the degree of supercooling.

\section{EXPERIMENTAL APPARATUS AND PROCEDURE}

The drop morphology, internal flow behavior, drop temperature variation and solidification front movement within an evaporating sessile drop with basecenter cooling is studied. The first objective was achieved through the use of the laser shadowgraphschlieren method, while the other two were accomplished by means of microscopic photography.

The center-cooling method was employed to cool the base center of a drop within which the solid phase

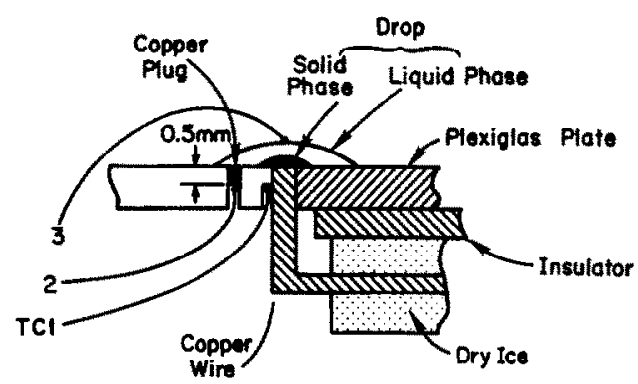

Fig. 1. A drop on the test plate.

would grow radially outward as shown in Fig. 1. A hole of $1 \mathrm{~mm}$ in diameter was drilled on a $130 \times 45 \times 3$ mm plexiglas plate. A copper wire was inserted through the hole with its tip flush with the upper surface of the plate. The wire was inserted into a block of dry ice which acted as a heat sink. Cyanocylate sealed the gap between the wire and the plate. The wire size was selected based on the degree of supercooling needed for the solidification of the drop. A minute drop was carefully placed on the test plate with its base center situated on top of the wire tip, using a No. 19 needle and a B-D Yale $0.5 \mathrm{ml}$ syringe.

The time history of drop temperature was monitored by three gauge No. 32 copper-constantan ther- 


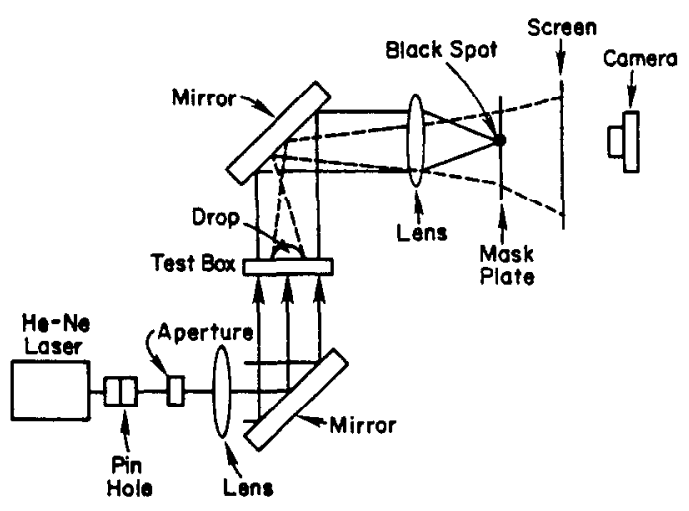

FIG. 2. Schematic diagram of shadowgraphy.

mocouples, as shown in Fig. 1. Thermocouples 1, 2, and 3 measured the drop temperatures at the base center, triphase point (base edge) and summit, respectively. The temperature signals were transmitted through an amplifier and recorded on Kodak linography direct print paper in a visicorder. The drop-center temperature reflected the degree of supercooling, while the temperature difference between the triphase point and the drop summit could be considered the surface temperature difference $\Delta T$ in the Marangoni number.

The drop morphology was recorded by the schlieren optical setup illustrated in Fig. 2. It consists of a $35 \mathrm{~mW}$, model 124B cylindrical heliumneon laser, pin hole, test plate, two aluminized mirrors, lens, mask plate, screen, and camera. The mask plate was a glass plate marked with a dark spot which was positioned at the focal point of the lens. Thus, it constituted a traditional schlieren technique with the knife edge being replaced by a dark spot. The solid lines in Fig. 2 illustrate the passage of laser beams which was completely blocked by the dark spot; instead of partially cut off by the knife edge as in the conventional schlieren method. The dashlines depict the light passage being deflected by the sessile drop which is eventually projected on the screen for display and photography.

For the observation of internal flow behavior and solidification front movement, fine, extra-brilliant No. 53 aluminum powders (as the tracer) were mixed homogeneously into the reagent in a test tube. By means of the syringe/needle unit, the liquid with powder suspension was placed as a drop on top of the copper-wire tip on the test plate. With the aid of a microscope, flow behavior was observed, while the movement of the solid-liquid phase boundary was recorded by multiple exposures of an ASA 3000 , $8.26 \times 8.26 \mathrm{~mm}$ polaroid film. Distilled water and some organic liquids with melting points of approximately $10^{\circ} \mathrm{C}$ were selected for flow observation. However, most organic reagents in the solid phase are opaque and thus unsuitable for multiple-exposure photography. The drops of distilled water and $p$ xylene, being transparent in thin solid, were tested for the movement of the solidification front. Their physical properties and drop dimensions are listed in Table 1.

\section{RESULTS AND DISCUSSION}

Figure 3 is a shadowgraph of an oleic acid drop on the plexiglas plate, viewed from the side. The dark rectangle showed the plate, on which a drop and a solid phase (dark) sat. The plate thickness measures $1 \mathrm{~mm}$. Figure 4 shows both the drop and the solid phase taking the form of spherical segments of different radii, $r_{1}$ and $r_{\mathrm{s}}$, respectively. $r$ and $z$ are two-dimensional, axisymmetrical coordinates with the original fixed at point 0 . The base radii of the drop and solid phase on the plate are $R$ and $R_{s}$, respectively, while

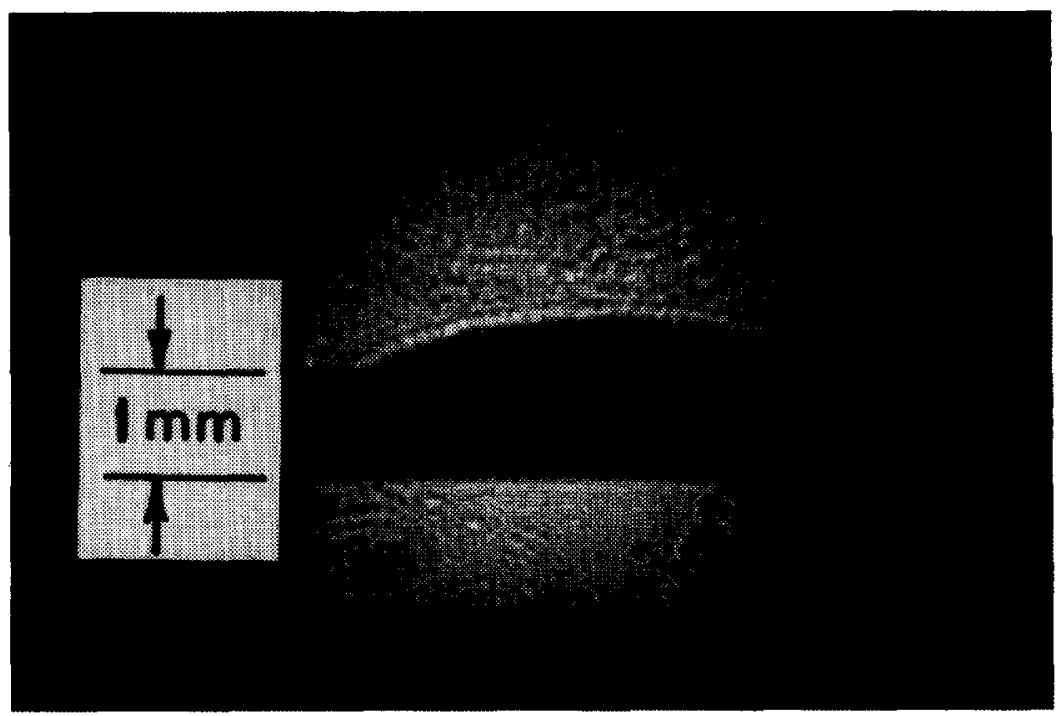

FIG. 3. Side view of an oleic acid sessile drop. 
Table 1. Drop dimension and reagent properties $\nmid$ near melting point

\begin{tabular}{|c|c|c|}
\hline \multirow[b]{2}{*}{ Property } & \multicolumn{2}{|c|}{ Liquid } \\
\hline & $\begin{array}{l}\text { Water } \\
\mathrm{H}_{2} \mathrm{O}\end{array}$ & $\begin{array}{c}p \text {-xylene } \\
\mathrm{C}_{6} \mathrm{H}_{4}\left(\mathrm{CH}_{3}\right)_{2}\end{array}$ \\
\hline $\begin{array}{l}\text { drop base } \\
\text { radius, } R[\mathrm{~m}]\end{array}$ & $3.0 \times 10^{-3}$ & $6.5 \times 10^{-3}$ \\
\hline drop height, $L[\mathrm{~m}]$ & $6.0 \times 10^{-4}$ & $5.0 \times 10^{-4}$ \\
\hline melting point, $T_{\mathrm{tn}}\left[{ }^{\circ} \mathrm{C}\right]$ & 0 & 13.3 \\
\hline $\begin{array}{l}\text { thermal conductivity, } \\
k\left[\mathrm{~kW} \mathrm{~m}^{-1} \mathrm{~K}^{-1}\right]\end{array}$ & $\begin{array}{l}0.555 \times 10^{-3} \\
\left(k_{\mathrm{s}}-2.21 \times 10^{-3}\right)\end{array}$ & $\begin{array}{l}0.134 \times 10^{-3} \\
\left(k_{\mathrm{s}}-0.131 \times 10^{-3}\right) \%\end{array}$ \\
\hline $\begin{array}{l}\text { specific heat, } \\
C_{p}\left[\mathrm{~kJ} \mathrm{~kg}^{-1} \mathrm{~K}^{-1}\right]\end{array}$ & $\begin{array}{l}4.217 \\
\left(C_{p \mathrm{~s}}=1\right)\end{array}$ & $\begin{array}{l}1.72 \\
\left(C_{p \mathrm{~s}}=0.9\right) \S\end{array}$ \\
\hline $\begin{array}{l}\text { density, } \\
\rho\left[\mathrm{kg} \mathrm{m}^{-3}\right]\end{array}$ & $\begin{array}{l}1000 \\
\left(\rho_{\mathrm{s}}=920\right)\end{array}$ & $\begin{array}{l}861 \\
\left(\rho_{\mathrm{s}}=861\right)\end{array}$ \\
\hline $\begin{array}{l}\text { dynamic viscosity, } \\
\mu\left[\mathrm{N} \mathrm{s} \mathrm{m}^{-2}\right]\end{array}$ & $17.89 \times 10^{4}$ & $7.7 \times 10^{-4}$ \\
\hline $\begin{array}{l}\text { heat of fusion, } \\
h_{1 \mathrm{~s}}\left[\mathrm{~kJ} \mathrm{~kg}^{-1}\right]\end{array}$ & 332.432 & 159.517 \\
\hline $\begin{array}{l}\text { thermal expansion } \\
\text { coefficient, } \beta\left[\mathrm{K}^{-1}\right]\end{array}$ & $-0.7 \times 10^{-4}$ & $1.02 \times 10^{-3}$ \\
\hline $\begin{array}{l}\text { surface tension, } \\
\sigma\left[\mathrm{N} \mathrm{m}^{-1}\right]\end{array}$ & 0.0756 & 0.0284 \\
\hline $\begin{array}{l}\text { surface tension gradient, } \\
\partial \sigma / \partial T\left[\mathrm{~N} \mathrm{~m}^{-1} \mathbf{K}^{-1}\right]\end{array}$ & $-1.6 \times 10^{-4}$ & $-1.0 \times 10^{-4}$ \\
\hline Prandtl number & 13.7 & 10 \\
\hline
\end{tabular}

† Data from refs. [15-17].

\pm Assumed value.

$\S$ Estimated value [18].

the drop height is $L$. For a spherical segment, the volume $V$ is related to the radius and chord length by

$$
V=\pi L\left(3 R^{2}+L^{2}\right) / 6 .
$$

In order to ascertain the drop geometry, the test plate was placed on a $10 \mathrm{~mm}$ engineering form. The chord length of the drop $2 R$ was read after a drop was placed on the plate by means of a syringe. The drop volume $V$ was determined from the volume change in the syringe. Then, equation (1) calculated the drop height $L$ which agreed very well with the measured value. Thus, one concludes that the sessile drop is a spherical segment in geometry.

\section{Morphology}

It was observed by the shadowgraph-schlieren method that there exist (i) three distinct flow struc-

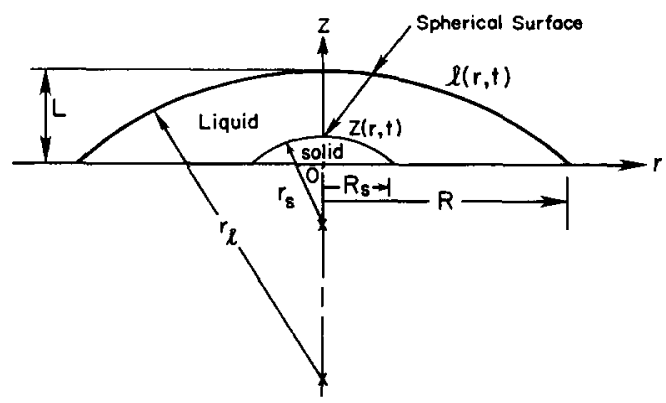

Fig. 4. Coordinates of a sessile drop. tures at the liquid-air interface: unstable (rippled drop surface), substable and stable (smooth drop surface) [19] and (ii) the surface characteristics of evaporating sessile drops remained the same throughout the entire process of internal solidification by the center-cooling method [19].

The present study determines the effects of internal solidification and test plate on the interfacial flow structure of evaporating sessile drops. Some typical shadowgraphs are presented in Fig. 5. Notice the shadow or the copper wire cutting through the drop periphery to reach the central region, in Figs. 5(a), (b), (c), and ( $\left.c^{\prime}\right)$. Figures 5(a) and (a') show the stableinterface type evaporation of cyclohexane drops with and without internal solidification, respectively. The finding suggests that the presence of internal solidification cannot change the stable-interface type evaporation. Two contour lines in Fig. 5(a) represent the drop periphery at two different instants of the evaporation process, indicating no change in the interfacial flow structure during the course of internal solidification.

Internal solidification can change the interfacial flow structure if the drop evaporation is of an unstable- or substable-interface type. Figures 5(b) and ( $\left.b^{\prime}\right)$ show such an example. The evaporation of a methanol drop on a glass plate belongs to the unstableinterface type, as seen in Fig. 5(b') [13]. When the same drop was placed on a plexiglas plate with center cooling, its shadowgraph exhibits a typical substable- 

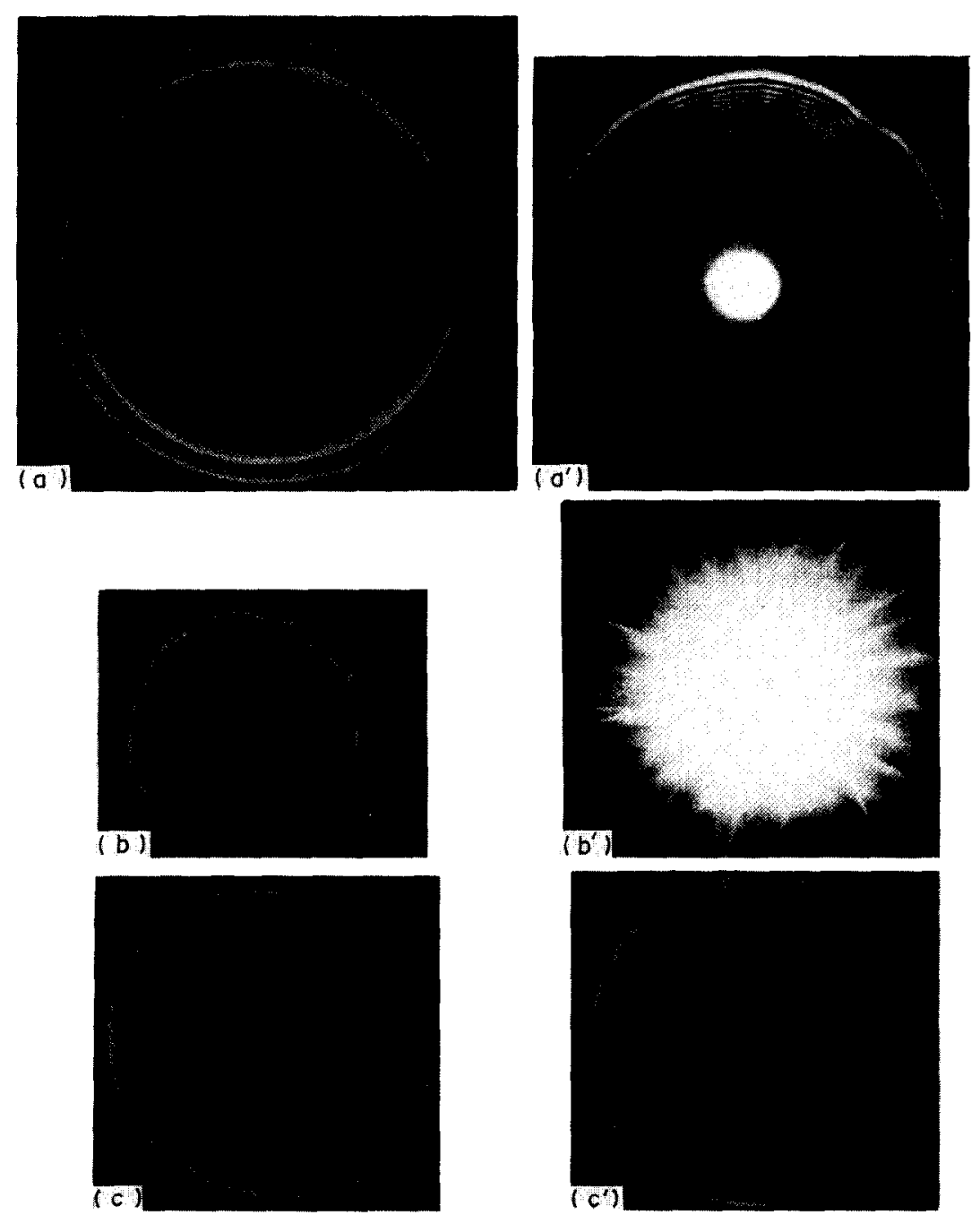

FIG. 5. Instant laser shadowgraph of various evaporation drops : (a) cyclohexane on plexiglas with internal solidification; $\left(a^{\prime}\right)$ cyclohexane on glass plate without internal solidification; (b) methanol on plexiglas plate with internal solidification; ( $\mathrm{b}^{\prime}$ ) methanol on glass plate without internal solidification ; (c) $p$-xylene on plexiglas plate with internal solidification; $\left(\mathrm{c}^{\prime}\right) p$-xylene on glass plate with internal solidification.

interface type evaporation as shown in Fig. 5(b). This change in the interfacial flow behavior due to internal solidification can be explained as follows: the unstable-interface type evaporation in Fig. $5\left(b^{\prime}\right)$ is characterized by the rippling of the drop surface which enhances the rate of evaporation. However, with center cooling, the imposed supercooling of the drop resulted in a larger temperature gradient and consequently a stronger thermocapillary force along the drop surface. This strong thermocapillary force suppressed the surface rippling of the evaporating drop, smoothing down the drop surface. In addition, the center cooling created a thermal field which increased in the radial direction from the drop center. With the surface region at a higher temperature than the center region, the drop surface became more stable than that in the absence of center cooling.

In order to prove that the physico-chemical charac- teristics of the test plate had no influence on the nature of interfacial turbulence in the presence of internal solidification, tests on the evaporation of $p$-xylene drops were repeated on a plexiglas plate under the identical situation as with the glass plate. Both Figs. 5(c) and ( $\left.c^{\prime}\right)$ show the stable-interface type evaporation. The variation of drop morphology on the plexiglas plate is identical with that which had occurred on the glass plate. Therefore, the contact conditions between the drop and the test plate of different materials do not influence the drop morphology.

\section{Drop temperature variation}

Figure 6 depicts the temperature time history of a $p$-xylene drop evaporating on a plexiglas plate with internal solidification. $T_{\mathrm{rm}}$ denotes the temperature of solidification. $T_{1}, T_{2}$, and $T_{3}$, are the temperatures at 


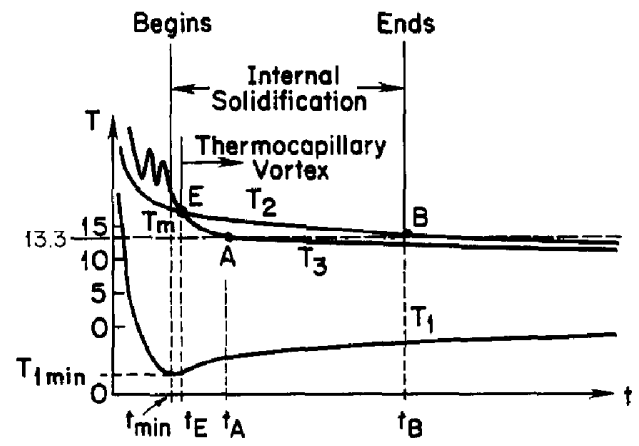

Fig. 6. Typical temperature time history of a $p$-xylene drop evaporating on a test plate with internal solidification.

the base center, edge (triphase point) and summit of the drop, respectively. All were initially at the ambient temperature, when the drop was placed on the plate. They decreased very rapidly beginning at the moment when the copper wire was put in contact with dry ice. The summit temperature $T_{3}$ fluctuated over a brief period of time, leveling off thereafter. The base center temperature $T_{1}$ dropped sharply, reaching a minimum $\left(T_{1 \min }\right)$ at the time instant $t_{\min }$, followed by a gradual rise. When $T_{1}$ reached its minimum value, liquid solidification was initiated at the base center corresponding to the coldest spot in the drop, $T_{1}$ rose thereafter as the solid phase continued to grow. The difference between $T_{\mathrm{m}}$ and $T_{1 \min }$ represents the degree of supercooling during which the drop was in a metastable state. The unique feature of the metastable state was evidenced by the fluctuation of $T_{3}$ which was associated with the unstable drop surface. Eventually, $T_{3}$ fell below $T_{2}$ and reached $T_{\mathrm{m}}$ (at point A) ahead of $T_{2}$ (at point $\mathrm{B}$ ) simply because the drop summit was located closer to the base center than the triphase point. Solidification reached the drop summit when $T_{3}$ dropped to point $\mathrm{A}$ and the entire drop became a solid when $T_{2}$ reached point B.

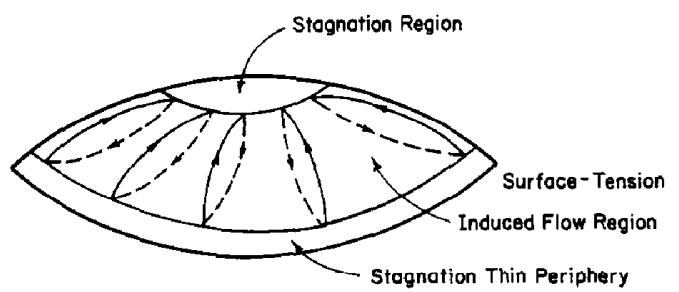

(a)

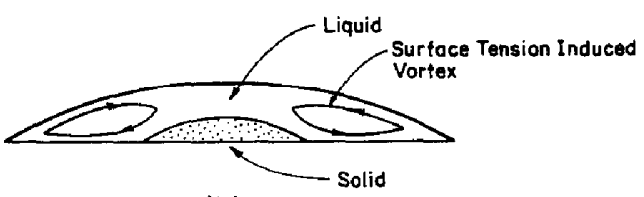

(b)

Fic. 7. Schematic diagram of nalural convection pattern in a drop evaporating on a test plate with internal solidification: (a) three-dimensional; (b) side view.

\section{Internal flow patterns}

Using aluminum powders as the tracer, the internal flow structure inside the drop was observed and photographed through a microscope. Various liquids were tested including $p$-xylene, cyclohexane, oleic acid, capric acid, methanol and others. Figure 7 shows a schematic diagram of the natural convection pattern in a drop evaporating on the test plate with internal solidification. Figures $7(\mathrm{a})$ and (b) are the threedimensional and side views, respectively. A stagnation region was observed at the drop summit around which a strong thermocapillary flow existed. Since the drop temperature was lower at the summit and higher at the base edge, the flow moved up along the drop surface and then radially downward, forming a roll shape. The phenomenon occurred after the time $t_{\mathrm{E}}$ in Fig. 6 when $T_{3}$ fell below $T_{2}$. The duration of $t_{\mathrm{F}}$ was usually short. There was no fluid motion in the narrow peripheral region outside the doughnut-shaped thermocapillary vortex region.

Figure 8 depicts the instant microscopic photographs $(40 \times)$ and the schematic top view of the corresponding flow pattern in an evaporating $p$-xylene drop at the initial $\left(t_{\mathrm{E}}\right)$, intermediate (near $\left.t_{\mathrm{A}}\right)$ and final (near $t_{\mathrm{B}}$ ) stages of internal solidification. The lefthand side of the photographs shows the solid phase, while the right-hand side is the trace of suspending aluminum particles in the liquid phase. The width of the doughnut-shaped flow region became progressively narrow with time, as seen in the sketches of Fig. 8. The fluid motion formed a circular path. In the final stage, a narrow thermocapillary flow region surrounded the solid phase near the triphase line, see Fig. 8(c). For organic reagents with lower Prandtl number such as $p$-xylene with $P r=10$, the flow velocity in the doughnut-shaped vortex was quite high, at many circulations per second. However, it is difficult to follow a specific tracer particle to determine its speed. The flow velocity was much slower in high Prandtl number organic reagents such as oleic acid with $\operatorname{Pr}=227$. In general, the thermocapillary flow velocity is retarded with an increase in the Prandtl number due to an increase in the dragging effect of viscosity. Since the direction of thermocapillary flow is opposite to that of solid growth, the solidification front velocity is inversely proportional to Marangoni number. High Prandt] number yields low thermocapillary flow but promotes solidification front velocity. On the other hand, high Prandtl number implies poor heat diffusion and low heat (of solidification) removal from the liquid phase, and consequently reduces the solidification front velocity. This is a paradox (conflicting physical phenomena) the incongruity of which depends on the strength of thermocapillary flow.

\section{Solid growth velocity}

It is imperative to determine the dimensionless parameters which govern the liquid motion and solid growth. Natural convection in an evaporating sessile 

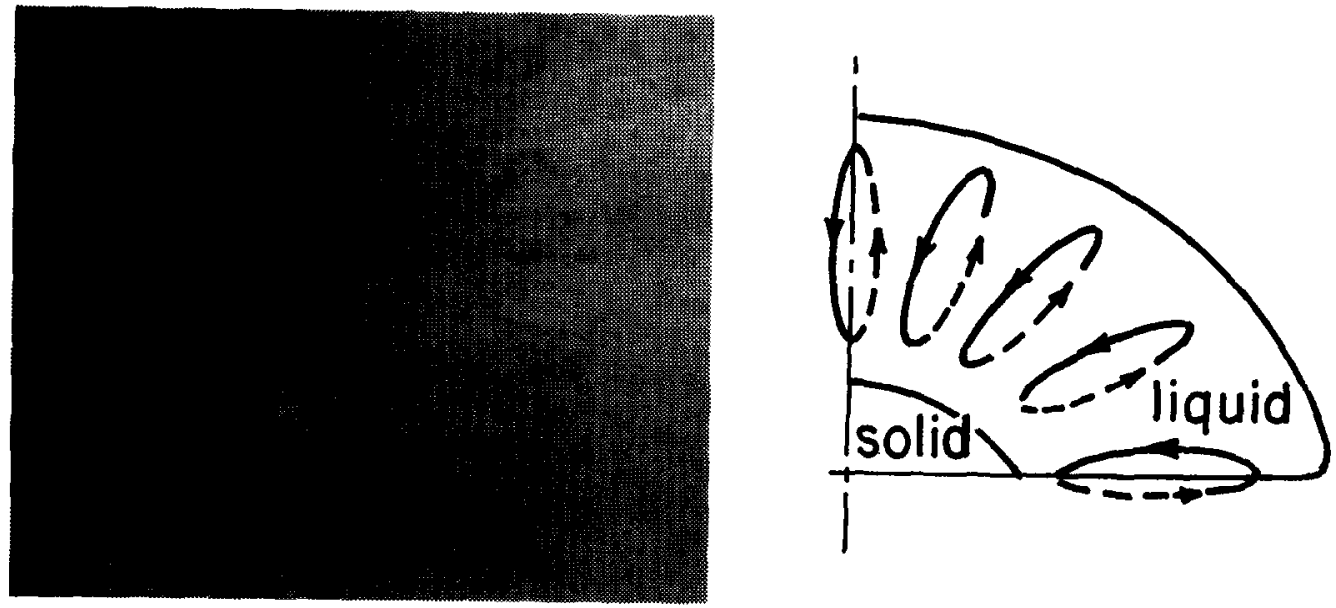

(a)
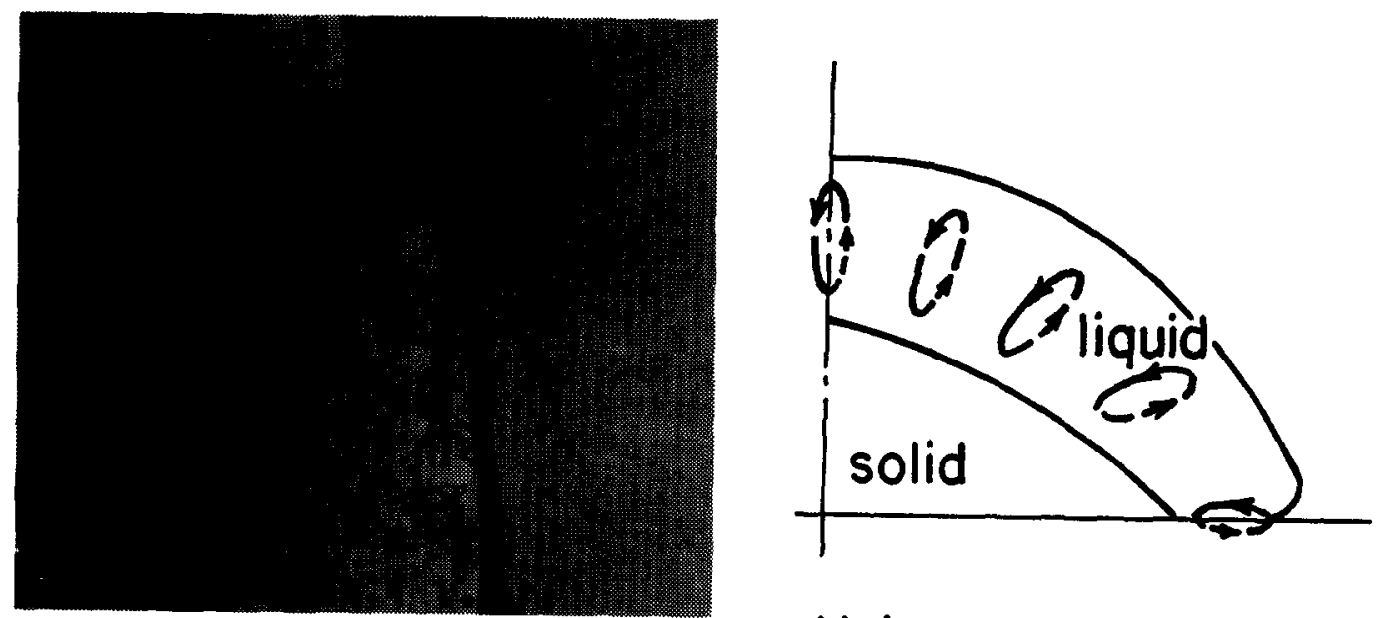

(b)
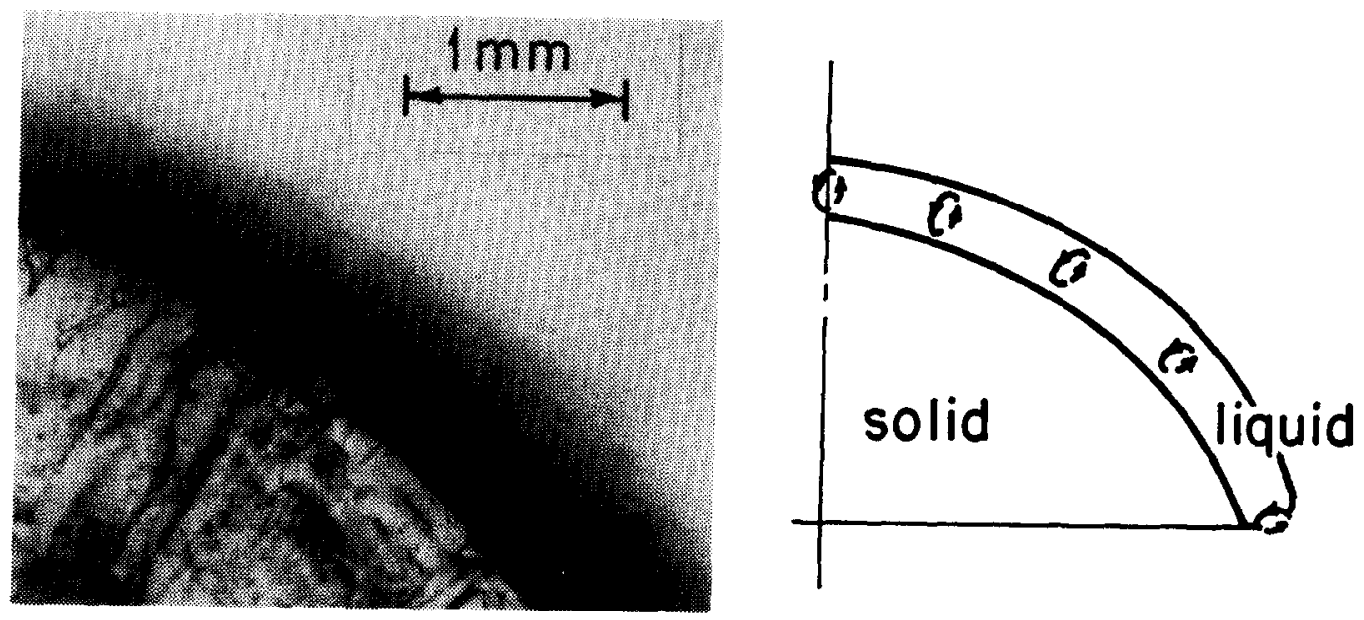

(c)

Fig. 8. Microscopic photographs $(40 x)$ and schematic top view of natural convection pattern in an evaporating $p$-xylene drop with internal solidification at: (a) initial; (b) intermediate; (c) final stages. 

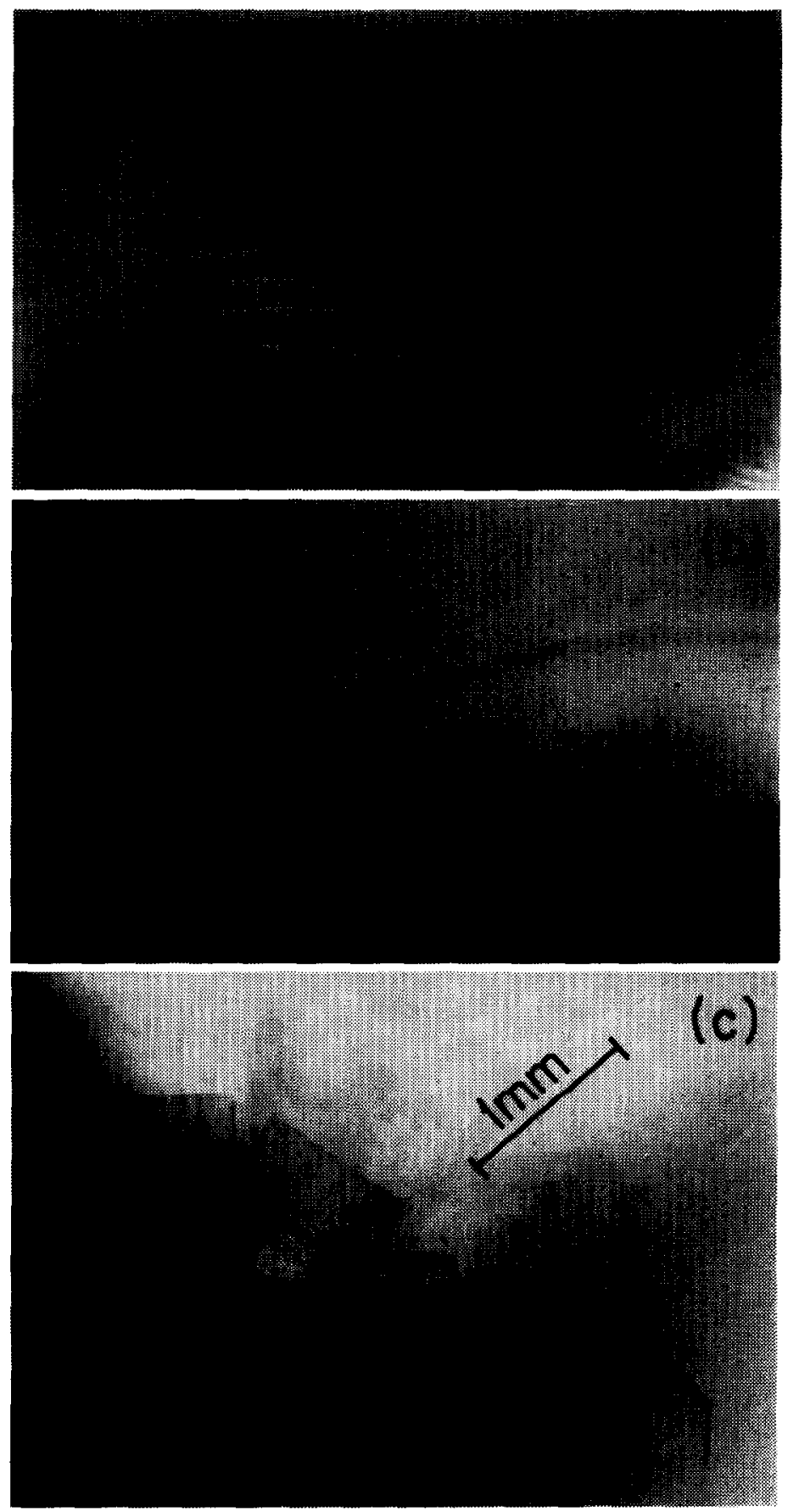

FIG. 9. Multiple-exposure photography of solidification front in the drops of (a) and (b) distilled water and (c) p-xylene; (b) solid structure formed at the interface region during the entire exposure time. 
drop involve the action of both buoyancy and thermocapillary forces, the magnitudes of which are related to the Rayleigh and Marangoni number, respectively. The Rayleigh and Marangoni number are defined respectively as

$$
\begin{array}{r}
R a=\frac{\rho g \beta \Delta T l^{3}}{\mu a}=\left(\frac{\text { enthalpy flow }}{\text { conduction }}\right) \\
\cdot\left(\frac{\text { buoyancy force }}{\text { viscous force }}\right) \\
M a=\frac{(\partial \sigma / \partial T) \Delta T l}{\mu a}=\left(\frac{\text { enthalpy flow }}{\text { conduction }}\right) \\
\cdot\left(\frac{\text { surface tension force }}{\text { viscous force }}-\overline{-}\right) .
\end{array}
$$

The relative importance of buoyancy and surface tension forces is represented by the dynamic Bond number defined as

$$
B d=\frac{\rho g \beta l^{2}}{\partial \sigma / \partial T}=\frac{\text { buoyancy force }}{\text { surface tension force }} .
$$

In the dynamic Bond number, the surface tension force is induced by the variation of surface tension to temperature gradient. However, in the traditional Bond number which is defined as $B o=\rho g l^{2} / \sigma$, the surface tension force is associated with the interfacial curvature. In the present study, the drop height $L$ which is selected as the characteristic length $l$ is of the order of $0.5-1 \mathrm{~mm}$. Using the data in Table $1, B d$ is found to be much smaller than unity. Hence, the effect of buoyancy force can be neglected.

As solid growth progresses, the heat of fusion is generated at the moving solid-liquid interface and must be removed through the liquid and solid phases. The interface temperature is not uniform at the melting temperature $T_{\mathrm{m}}$ as indicated by the Gibbs-Thompson capillary effect. It should be a function of the dendritic curvature as

$$
T_{\mathrm{e}}=T_{\mathrm{m}}\left[1-\frac{\gamma}{\rho_{\mathrm{s}}} \bar{h}_{\mathrm{ls}}\left(\frac{1}{R_{1}}+\frac{1}{R_{2}}\right)\right]
$$

where $T_{\mathrm{e}}$ denotes the equivalent interface temperature and $R_{1}$ and $R_{2}$ are the radii of the principal curvatures. For the water drop, $\gamma=78.2 \times 10^{-6} \mathrm{~kJ} \mathrm{~m}^{-2} ; \rho_{\mathrm{s}}=913$ $\mathrm{kg} \mathrm{m}^{-3}$; and $h_{\mathrm{s}}=332 \mathrm{~kJ} \mathrm{~kg}^{-1}$, equation (5) gives $T_{\mathrm{e}}=T_{\mathrm{m}}$ for the curvature of $0.1 \mu \mathrm{m}$. Therefore, the heat balance at the solid-liquid interface of the Stefan type phase-change problem gives

$$
\rho_{\mathrm{s}} v h_{\mathrm{ls}}=k_{\mathrm{s}} \frac{\left(T_{\mathrm{m}}-T_{1}\right)}{R_{\mathrm{s}}}+h\left(T_{\mathrm{m}}-T_{2}\right) .
$$

Upon the substitution of $N u=h l / k$, equation (6) can be rewritten as

$$
\frac{v R_{\mathrm{s}}}{a_{\mathrm{s}}}+N u\left(\frac{R_{\mathrm{s}}}{l}\right)\left(\frac{a_{1}}{a_{\mathrm{s}}}\right)\left(\frac{\rho_{1}}{\rho_{\mathrm{s}}}\right) S t=S .
$$

Here, $S t$ denotes the Stefan number and $S$ is the degree of supercooling in dimensionless form. For buoyancyinduced convection, $N u$ is a function of $R a$ and $P r$. In the thermocapillary convection case $R a$ is replaced by $M a$. The property $a_{1}$ is reflected by $P r$, while $\rho_{1} / \rho_{\mathrm{s}}$ can usually be neglected for a small-scale system. The ratio $R_{\mathrm{s}} / /$ is defined as the aspect ratio $A$. Thus, equation (7) implies

$$
\frac{v R_{\mathrm{s}}}{a_{\mathrm{s}}} A M a^{n} P r^{m} S t^{q} \simeq f(S)
$$

Here, $m, n$ and $q$ are exponents to be experimentally determined.

The solid growth velocity was experimentally determined by multiple-exposure photography of the moving solidification front through a microscope. Figures 9(a) and (c) are the multiple-exposure photographs of the solidification fronts within the drops of distilled water and $p$-xylene, respectively. The exposure time interval in Fig. 9(a) was 20 s. Each line represents the solid-liquid interface at a certain instant, with the scale for a $1 \mathrm{~mm}$ length marked on the photographs. With the distance between two solidification fronts and the corresponding time interval known, the solid growth velocity $v$ can be calculated. It is seen in both Figs. 9(a) and (c) that the solidification velocity reduces with an increase in the solid base radius $R_{\mathrm{s}}$. When the camera was focused on the solid region in a distilled water drop, Fig. 9(b) exhibited an ice layer (marked 'solid') formed during the entire exposure time.

The relationship between the solid growth velocity $v$ and the base radius of the solid phase $r$ is schematically shown in Fig. 10. Since the focal distance between the camera lens and the solid-liquid interface changed rapidly during the initial stage of internal solidification, only the solid growth velocity during the intermediate stage can be measured. During the final stage, the movement of the solidification front became too slow for multiple-exposure photography. Although many liquids were tested, the quantitative evaluation of the solid growth velocity was limited to the reagents the solid phases of which were transparent. Thus, the quantitative results of only distilled water and $p$-xylene were presented in dimensionless form as $v^{*}$ vs $S$ in Fig. 11. Here, $v^{*}$ is defined as

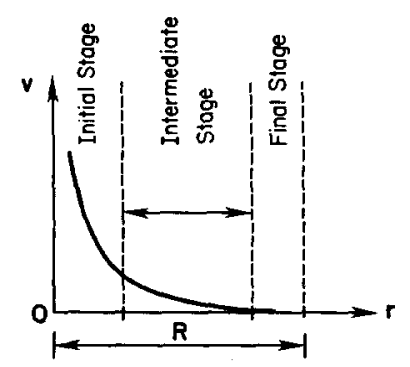

FiG. 10. Solid growth velocity vs base radius of solid phase. 


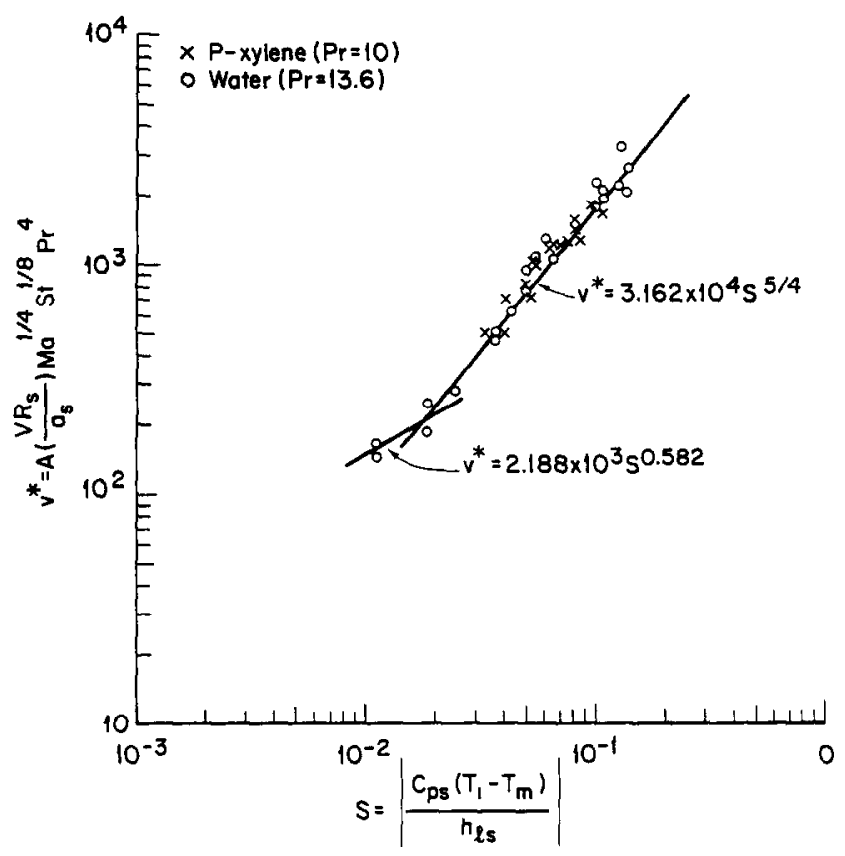

Fig. 11. Correlation of $v^{*}$ vs $S$ for low $\operatorname{Pr}$ liquids (water and $p$-xylene drops).

$$
v^{*}=\left(\frac{V R_{\mathrm{s}}}{a_{\mathrm{s}}}\right) A M a^{1 / 4} \operatorname{Pr}^{4} S t^{1 / 8} .
$$

This plot is valid for the reagents with a low Prandtl number of the order of 10 . Two straight lines of different slope were drawn through the data

$$
v^{*}=2.188 \times 10^{3} S^{0.582}
$$

for $S \leqslant 0.019$ and

$$
v^{*}=3.162 \times 10^{4} S^{5 / 4}
$$

for $S \geqslant 0.019$. Equations (10) describe the effects of $M a, P r, S t$ and $S$ on the solid growth velocity. Both equations (10a) and (10b) indicate that the solid growth velocity $v$ depends most strongly on $\operatorname{Pr}$ and less on $S, M a$ and $S t$ (in decreasing order), while $v$ is proportional to $\mathrm{Pr}, \mathrm{Ma}$ and $S t$ but is inversely proportional to $S$.

\section{CONCLUSIONS}

Thermocapillary force plays an important role in the morphology, internal flow behavior, temperature, and solidification velocity in an evaporating sessile drop being point-cooled at its base center. The shadowgraph-schlieren method and microscopic photography have been employed in the study. The following conclusions can be drawn.

(1) The air-liquid interfacial morphology can be changed from the unstable-evaporation type to the stable one by the center cooling of the drop. The change is achieved by a thermocapillary force which suppresses the rippling on the drop surface. The drop surface characteristics, irrespective of stable- or unsta- ble-evaporation type, remains unchanged during the course of solid growth.

(2) There exists a doughnut-shaped, thermocapillary-induced vortex region surrounding the growing solid phase inside an evaporating drop. However, the role of Prandtl number on the solid growth is a paradox: a high Prandtl number yields a low thermocapillary flow which promotes the solid growth velocity. On the other hand, a high Prandtl number implies slow removal of the heat of fusion which suppresses the solid growth rate.

(3) For the reagents with $\mathrm{Pr}$ of the order of 10, two correlation equations are obtained which relate the dimensionless degree of supercooling to a dimensionless parameter including $\mathrm{Ma}, \mathrm{Pr}, \mathrm{St}$, aspect ratio and solid growth velocity.

(4) The measurement of drop temperatures at the base center, triphase line (base edge) and summit reveals the information concerning the genesis of internal solidification and thermocapillary vortex.

(5) The geometrical shape of both the evaporating sessile drop and the solid phase growing inside the drop take the form of a spherical segment which can be used in a theoretical study.

\section{REFERENCES}

1. S. G. Bankofr, Heat conduction or diffusion with change of phase. In Advances in Chemical Engineering, Vol. 5, pp. $75-150$ (1964).

2. J. R. Ockendon and W. R. Hodgkins, Moving Boundary Problems in Heat Flow and Diffusion. Oxford University Press, Oxford (1975).

3. D. G. Wilson, A. D. Solomon and P. T. Boggs, Moving Boundary Problems. Academic Press, New York (1978). 
4. S. M. Pimputkar and S. Ostrach, Convective effects in crystals grown from melt, J. Crystal Growth 55, 614-646 (1981).

5. S. Ostrach, Fluid mechanics in crystal growth - the 1982 Freeman Scholar Lecture, J. Fluids Engng 105, 5-20 (1983).

6. M. Epstein and F. B. Cheung, Complex freezing-melting interfaces in fluid flow, Ann. Rev. Fluid Mech. 15, 293319 (1983).

7. M. E. Glicksman, S. R. Coriell and G. B. McFadden, Interaction of flows with the crystal-melt interface, $A n n$. Rev. Fluid Mech. 18, 307-335 (1986).

8. S. Ostrach, Low-gravity fluid flows, Am. Rev. Fluid Mech. 14, 313-345 (1982).

9. C. V. Sternling and L. E. Scriven, Interfacial turbulence: hydrodynamic instability and Marangoni effect, A.I.Ch.E. Jl 5, 514-523 (1959).

10. D. B. R. Kenning, Two phase flow with nonuniform surface tension, Appl. Mech. Rev. 21, 1101-1111 (1968).

I1. C.-H. Chun and W. Wuest, A micro-gravity simulation of the Marangoni convection, Acta Astronautia 5, 681 686 (1978).

12. D. Schwabe, A. Scharmann, F. Preisser and F. Oeder,
Experiments on surface tension driven flow in floating zone melting, J. Crystal Growth 43, 305-312 (1978).

13. W. J. Yang, Natural convection in evaporating droplets. In Handbook of Heat and Mass Transfer Operations (Edited by N. P. Chermisinoff), Vol. 1, Chap. 6, pp. 211-229. Gulf, West Orange, New Jersey (1986).

14. J. C. Duh, Thermocapillary-buoyancy convection in drop-shaped system by phase change, Ph.D. thesis, Department of Mechanical Engineering and Applied Mechanics, University of Michigan, Ann Arbor, Michigan (1987).

15. R. C. Weast, CRC Handbook of Chemistry and Physics, GGtlı Edn. CRC Press, Boca Raton, Florida (1985).

16. C. L. Yaws, Physical properties. In Chemical Engineering. McGraw-Hill, New York (1987).

17. Raznjevic, Handhook of Thermodynamir Tables and Charts. Hemisphere, Washington, D.C. (1976).

18. J. A. Dean, Lange's Handbook of Chemistry, $13 \mathrm{Edn}$. McGraw-Hill, New York (1985).

19. W. J. Yang, G. Kawashima, P. P.-T. Yang and J. Lin, Natural convection in evaporation sessile drops with crystal growth, Int. Commun. Heat Mass Transfer 14, 265-280 (1987).

\title{
CONVECTION NATURELLE AUTOUR DE GOUTTES EN EVAPORATION AVEC SOLIDIFICATION
}

Résumé--La convection naturelle transitoire et la solidification interne dans une goutte qui s'évapore sur une plaque horizontale est étudiée par la méthode laser d'ombre-schlieren et la photographie microscopique directe. La goutte est ponctuellement refroidie au centre de la base par le sommet d'un fil métallique connecté à un bloc de glace sèche. Une région de tourbillon induit par thermocapillarité existe autour de la phase solide au cours de la solification interne. La genèse de l'anneau tourbillonnaire et la solification interne peuvent être prédites à partir de l'évolution de température dans le temps. La solification interne supprime les rides superficielles de la goutte qui s'èvapore, ce qui retarde l'évaporation. Des expressions empiriques sont obtenues qui décrivent les effets des nombres de Marangoni, de Prandtl et de Stefan et du degré de sous-refroidissement sur la vitesse de croissance solide.

\section{NATÜRLICHE KONVEKTION IN KONDENSIERENDEN NICHTGLEITFẌHIGEN TROPFEN MIT ERSTARRUNG}

\begin{abstract}
Zusammenfassung--Mit Hilfe der Laser-Schatten-Schlieren-Methode und direkter mikroskopischer Fotografie wird die instationäre natürliche Konvektion und innere Erstarrung in einem sehr kleinen Tropfen untersucht, der an einer horizontalen Platte kondensiert. Der Tropfen wird punktförmig und mittig durch die Spitze eines Metalldrahtes gekühlt, der mit einem Trockeneisblock verbunden ist. Aufgrund der Thermokapillareffekte entsteht ein torustörmiges Wirbelgebiet um die feste. Phase während der inneren Erstarrung. Die Entstehung eines Wirbelringes aufgrund von Thermokapillareffekten und der inneren Erstarrung kann durch die Vorgeschichte der Tropfentemperatur vorhergesagt werden. Die innere Erstarrung unterdrückt Oberflächenwellen an einem kondensierenden Tropfen, wodurch die Kondensationsrate reduziert wird. Es werden empirische Korrelationen ermittelt, welche den Einfluß der Marangoni-, der Prandtl- und der Stefan-Zahl und den Grad der Unterkühlung auf die Wachstumsgeschwindigkeit der festen Phase beschreiben.
\end{abstract}

\section{ЕСТЕСТВЕННАЯ КОНВЕКЦИЯ В ИСПАРЯЮЩИХСЯ НЕПОДВИЖНЫХ КАПЛЯХ В ПРОЦЕССЕ ИХ ЗАТВЕРДЕВАНИЯ}

\begin{abstract}
Аннотаца - $C$ помоцью лазерного теневого метода и непосредственной микрофотосъемки исследовались нестационарная естественная конвекция и процесс затвердевания маленькой капли, испаряющейся на горизонтальной пластине. Проводилось точечное охлаждение капли путем подвода в центр ес основания конца металлической проволочки, соединснной с куском сухого льда. В процессе внутреннего затвердевания вокрут твердой фазы наблюдалось течение тороидальной формы, вызванное термокапиллярными эффектами. Возникновение этого вихревого течения и процесс внутреннего затвердевания могут быть рассчитаны из изменения во времени температуры капли. Процесс внутреннего затвердевания подавляет образование капиллярных волн на поверхности испаряющейся капли, уменышая таким образом скорость испарения. Получены эмпирические соотношения, описываюшие влияние чисел Марангони, Прандтля и Стефана и степени переохлаждения на скорость образования твердой фазы.
\end{abstract}

